\title{
Analysis on the Current System of China's Low-carbon Fiscal and Tax Policies: Based on the Analysis of the Policy Text
}

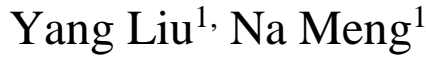 \\ ${ }^{1}$ School of Government, Beijing Normal University, Beijing 100875, China
}

\begin{abstract}
For the evaluation of the content of the existing China 's low-carbon fiscal and taxation policy system. This paper uses quantitative analysis of policy texts, through quantitative analysis and content mining of China 's low-carbon fiscal and taxation policy text since 2014, it is found that China 's current low-carbon fiscal and taxation policy is limited by the system. Under the influence of factors such as status lock, the problems of simplification, fragmentation, and insufficient process control of low-carbon fiscal and taxation policy tools are widespread. In the future, the system and mechanism should be deepened from the decisive role of catering to market resources reform.
\end{abstract}

Keywords: China, low-carbon fiscal and tax policies, analysis of the policy texts, current policy system

\section{INTRODUCTION}

The low-carbon economy is an economic development model characterized by low energy consumption and low emissions. Development and emission reduction are both the main principles of a low-carbon economy. Technological innovation is the key to the development of a low-carbon economy. The increase in the proportion of traditional energy efficiency, renewable energy production and consumption is the main path for the development of a low-carbon economy. Therefore, encouraging technological innovation, improving energy efficiency, and developing new energy sources have become the focus of developed countries in formulating low-carbon fiscal and taxation policies [1]. The core of the development of a low-carbon economy is carbon emission reduction. Due to the international and intergenerational externalities of carbon emission reduction, it is important to formulate reasonable and appropriate low-carbon fiscal and taxation policies. Therefore, to study the fiscal and taxation policies of China's low-carbon development, we must first sort out and explore the low-carbon fiscal and taxation policies themselves.

\subsection{Related Work}

According to the generation type of assumptions, we divided the existed work into five perspectives.

Chinese and Western comparative analysis perspective. Because of the low-carbon economy in developed countries, it has a wealth of practical experience in mobilizing market mechanism flexibility and using lowcarbon fiscal and taxation policies to develop a low-carbon economy [2], to make a horizontal comparison with
China's existing low-carbon policies, in order to achieve the effect of complementing each other. The low-carbon economy, as a concept directly related to coping with global climate change, has become a flexible means of coordinating between developed and developing countries. Microeconomics perspective. The low-carbon fiscal and taxation policy is at the macro level, and the implementation object of the policy is at the micro level. In order to better study the inherent driving mechanism of the low-carbon economy, some scholars have adopted the partial equilibrium analysis method, with producers and consumers as the analysis object, and explained the promotion of the low-carbon economy development through different combinations of fiscal and tax policies by constructing geometric models effect [3].

Design perspective of tax system. Carbon tax is one of the effective economic measures to reduce carbon emissions which is highly regarded by economists. This perspective advocates the introduction of a carbon tax and the establishment of a comprehensive carbon tax law system. In June 2010, China's National Development and Reform Commission and the Ministry of Finance jointly issued a special report entitled "Design of China's Carbon Tax Framework", and research into the design of the tax system has gradually focused on discussing taxpayers, collection links, tax bases and tax rates for carbon taxes [4] and other aspects [5].

Perspective of policy chain. The theory holds that in order to ensure the sequential connection of vertical and horizontal structures, the level of matching, and the complementary content of policies, the policy chain system is in order to effectively overcome the isolation and limitations of policies, thereby facilitating the overall function of policies [6]. Researchers have pointed out that the development of a low-carbon economy must systematically innovate national energy policies, industrial 
policies, economic policies, citizen participation in social policies, science and technology and talent policies, consumption policies, and cultural policies from the perspective of policy chain [7].

Analysis of policy text. Policy text analysis is further divided into pure policy text interpretation and policy text quantitative analysis. Quantitative analysis methods of policy text often used in research include word frequency statistics and co-word analysis. Co-word analysis is a method of quantifying the literature and is used to study the co-occurrence of keywords [8]. The policy text is a normative document, and the keywords of the text can comprehensively reflect the focus and hotspot of lowcarbon policies. Co-word analysis is based on the construction of a co-word matrix based on the number of occurrences of keywords in the same document. The coword matrix is obtained through analysis to determine the affinity between these keywords, and then to analyse the topic structure they represent, suitable for analysis of policy text and policy structure [9].

\subsection{Our Contribution}

Analysis of China's low-carbon fiscal and taxation policy system can use textual qualitative research tools to aggregate, encode, and classify the content of policy texts, and systematically summarize the footholds and priorities of the low-carbon fiscal and taxation policy system and their trends. This paper draws on the perspective of policy texts and uses this method to quantify the representative low-carbon policies in China from 2014 to 2019 and quantify the text to visually show the architecture of China's low-carbon policies. Compared with the research results of the low-carbon policy text, it focuses on analysing the composition and situation of low-carbon fiscal and taxation policies

\section{METHODOLOGY}

\subsection{Collection and selection of policy texts}

The existing research have studied the policy composition of the texts of China 's low-carbon policies from 1992 to 2013. Therefore, in this chapter, the texts of China 's lowcarbon policies from 2014 to 2019 are used for research. Text quantitative analysis. Search in the "Peking University magic weapon" according to the keywords "low carbon", "energy saving and emission reduction", "sustainable development", "environmental protection", "green", and "climate change", and found that from 2014 to 2019 , During the year, the policy documents related to low-carbon policies were mainly concentrated in the three "regulation categories" of "energy conservation management", "comprehensive environmental protection regulations", and "environmental protection / energy conservation and comprehensive utilization of resources".
In the period from 2014 to 2019 , conduct a comprehensive search from these three "regulatory categories", and delete policy documents that lack keywords such as catalogues, event notifications, technology collection, and promotion, such as annual updates. In the end, 19 highly relevant policy texts were selected, including 1 law, 2 State Council regulatory documents, and 16 department regulations; the main body of the release included the Standing Committee of the National People's Congress, the State Council, and various ministries and commissions of the State Council, all of which belong to the central laws and regulations. The level of validity of the interpretation has a wide scope.

\subsection{Extraction and induction of keywords}

First, keywords are manually extracted. By carefully reading each policy document, policy keywords related to low carbon were extracted. From the statistical results, there are a large number of invalid keywords and synonyms, which cannot be used for co-word analysis in the next step, and it needs to be standardized.

Secondly, need to discuss with public management professionals, and finally summarize the following two similar keywords: one is synonymous replacement, such as "energy-saving power generation dispatch" and "environment-friendly power dispatch", "leader plan" And the "leader system"; the other category is overlapped parts of speech, such as "government procurement" and "government green procurement", "emission trading" and "paid use and trading of emission rights". (3) Determination of keyword categories. Policies and regulations usually include three constituent elements: policy objectives, role objects, and means of action. Because low-carbon policies have a broad scope and complex structure, the focus of low-carbon policy formulation is on the innovation of means of action. In order to reflect the tool value of the policy, keywords are selected from the perspective of the means of the policy and coded for data analysis.

At last, after the above steps, 40 keywords were obtained, with a cumulative frequency of 499 times and an average frequency12.475 times, which basically covered China's low-carbon policy tools in the past 6 years.

\subsection{Data processing}

In this section, this chapter uses Python to extract the above 40 keywords from the text and count the word frequency, and then form a co-occurrence matrix with Bibexcel software. Because there are too many zero values in the co-occurrence matrix, in order to eliminate the influence caused by its own frequency difference and avoid excessive errors in statistics, the above cooccurrence matrix is subtracted from "1" in Excel to obtain a dissimilarity matrix. This dissimilarity matrix represents the degree of dissimilarity between pairs of keywords. The higher the number of different matrix, the smaller the 
degree of correlation of two words, the distance between keywords farther.

\subsection{Two-dimensional scale analysis}

Finally, using the SPSS statistical software, the dissimilarity matrix of 40 multidimensional scale keywords was reduced and iterated, and the twodimensional scale analysis was performed to obtain the corresponding Euclidean distance scatter plot (see Figure 1). By multi-dimensional analysis, Stress $=0.19083$; RSQ $=0.65127$. Since Stress values are below 0.2 and RSQ values are above 0.6 , so the results are credible.

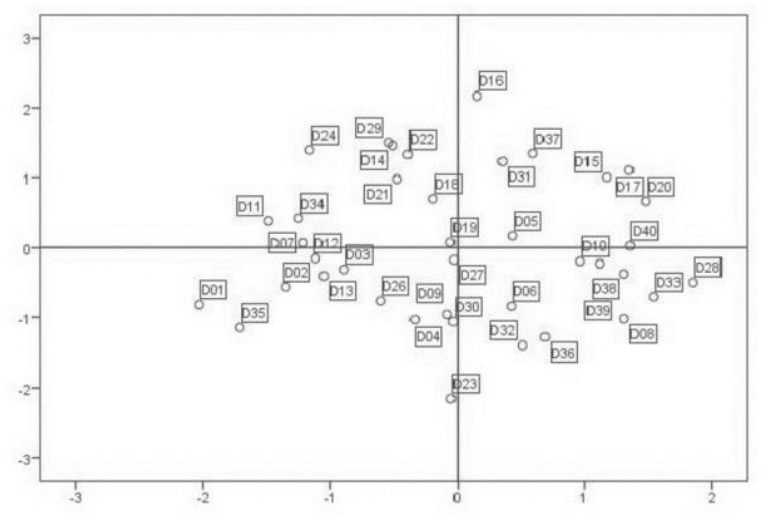

Figure 1 Low carbon policy system (2014-2019)

\section{ANALYSIS OF THE CONNOTATION AND SITUATION OF THE POLICY TEXT}

Multidimensional scale analysis specifies the conceptual space of observations (usually two or three dimensions) to a specific location, and finds the data structure by measuring the distance between observations. In the Euclidean distance scatter diagram, the observations are distributed in points, and the position of each point shows the degree of co-occurrence between keywords in the policy text. Highly co-occurring keywords will cluster with each other. Keywords that are closer to the central axis, especially closer to the origin (that is, closer to the two central axes of the horizontal and vertical axes at the same time) are more core.

As can be seen in Figure 1, the 40 keywords show the characteristics of "large mixed living", and the degree of co-occurrence is high, which is related to small text and multiple keywords. Because the model is effective, the overall concentration of keywords reflects the rapid and frequent introduction of China's low-carbon policies and policies in just 4 years. The 40 keywords extracted from the four-year policy introduction have included 38 policy tools in 22 years. The new policy tools are D39 emissions trading and D40 resource tax. Ad valorem reform; and the total frequency of 499 times for 40 policy instruments is very close to the total frequency of 508 times for 38 policy instruments. The newly added policy tools from 2014 to
2019 once again reflect the Chinese government's emphasis and determination on the development of a lowcarbon economy. However, it is worth noting that the close and frequent introduction of policies makes it easy to make policy goals short-term, induce short-sighted behaviour, and is not conducive to long-term development.

China 's low-carbon fiscal and taxation policies are jointly implemented by D16 tax incentives, D17 environmental tax reform, D20 incentives, D21 government procurement, D23 financial subsidies, D26 energy-saving products benefiting people projects, and D40 resource tax ad valorem reform Make up. The seven keywords are distributed discretely throughout the Euclidean distance scatter plot. It can be seen that the frequency of using similar tools in a policy text at the same time is low and the system needs to be improved. At the same time, there are many adjacent policy tools, involving different lead and implementation of the main sector, and the fragmentation of sector cooperation may affect the effect of the policy, resulting in insufficient government control over the fiscal and taxation process. Among these seven keywords, compared with other five similar policy tools, D21 and D26 are closest to the origin. Therefore, the government procurement and energy-saving products Huimin Project are more favoured by the government in this 4-year low-carbon policy. Tool of. At the same time, D23 and D40 fall on the vertical and horizontal axes, respectively, indicating that fiscal subsidy and resource tax ad valorem reform are important components of lowcarbon fiscal and taxation policies.

Policy tools are the means, methods and measures to achieve specific policy goals. According to the strength of the government's courage, the policy tools are divided into three types: mandatory, hybrid, and voluntary. Based on this theory, this chapter classifies China's low-carbon policies from 2014 to 2019 according to the classification criteria of regulatory, economic incentive, and society. regulatory policies dominate both the number of policy tools and the frequency of major categories, with the major category frequency of 13.81 exceeding the average frequency of 12.475. In contrast, the economic incentive category was slightly weaker. There are 11 types of this kind of tools, and the frequency is only 10.36, which is the least among the three types.

A careful analysis of the percentages of small frequency categories shows that low-carbon fiscal policies are still dominated by government-led expenditure policies (47.58\%), supplemented by tax adjustments (32.26\%). Compared with before 2013, only one type of fiscal and tax policy tools has been added, and the problem of singularity of fiscal and tax policy tools still exists.

\section{CONCLUSION}

In preparation for the quantitative analysis of the text of China 's low-carbon fiscal and taxation policies, this article still manually selects the content of the policy text itself. 
Simplification of low-carbon fiscal and taxation policy tools. Looking at the mature low-carbon fiscal and taxation policy tools in Western countries, the use of China's lowcarbon fiscal and taxation policy tools tends to be conservative. In terms of absolute and relative quantities, China's low-carbon fiscal and taxation policy tools are too singular, with incomplete supporting facilities, difficult to implement policies, and obvious isolation characteristics. Although this research is abundant in the global academic community, it is one of the few adopted by Chinese policy makers.

The fragmentation of the low-carbon fiscal and taxation policy system is mainly reflected in two aspects: on the system, because the low-carbon fiscal and taxation policy itself has a small number of tools, it is usually used together with other types of tools, especially with a wide range of government-regulated policies. The collaborative implementation of multiple departments dilutes the due role of fiscal and tax policies, fragmenting the low-carbon fiscal and taxation system. Institutionally, the low-carbon fiscal and taxation policy does not have its own independent taxes.

Insufficient process control for low-carbon fiscal and taxation policies. Administratively, multi-sector collaboration has also led to China's low-carbon fiscal and taxation policy system being unable to make timely feedback on policy implementation in a timely manner, reducing its grasp of the process. Although in the Supplementary Notice of the Development and Reform Commission of the Ministry of Finance on the Comprehensive Demonstration of Fiscal Policies for Energy Saving and Emission Reduction, issued on February 23, 2017, the process control of fiscal and tax policies was compensated, and too much remained in administrative punishment. No broader improvement.

This paper uses the co-word analysis method. Through quantitative analysis and content mining of the text of China 's low-carbon fiscal and taxation policy from 2013 to 2017 , it is found that although China 's current lowcarbon fiscal and taxation policy is working hard, it is limited. Due to factors such as institutional status lock-in, the problems of simplification, fragmentation, and insufficient process control of low-carbon fiscal and taxation policy tools are still widespread. The rational use of low-carbon fiscal and taxation policy tools is an important means of developing a low-carbon economy. The tilt of fiscal and taxation policies from fiscal policy to taxation policies also caters to the current era of deepening institutional reforms that allow the market to play a decisive role in resource allocation.

\section{REFERENCES}

[1] Chen Xinping. Fiscal and taxation policies under the development model of low-carbon economy: experience and enlightenment of developed countries, Macroeconomic Management, 2010 (04), pp.39-41.

[2] Wang Hua, Chen Yuanxin. Development of lowcarbon economy, transition of low-carbon economy and fiscal protection. Fiscal Research, 2011(10), pp.28-36.

[3] Su Xiaolong, Shen Manhong. Two-wheel drive for the development of a low-carbon economy: resource price reform and fiscal and tax policy innovation. Learning and Practice, 2010(12), pp.20-26.

[4] Su Ming, Fu Zhihua, Xu Wen, et al. China's carbon tax policy design and conception in the new situation. Local Finance Research, 2010(01), pp.28-37.

[5] Shen Manhong, He Zhenchuan, Meng Aihong. Financial and tax policy innovation from the perspective of a low-carbon economy. Poyang Lake Academic Journal, 2011(03), pp.10-16.

[6] Li Wujun, Huang Bingnan. Study on the Paradigm of China's Low-Carbon Economic Policy Chain. China's Population, Resources and Environment,2010 (10), pp.4352.

[7] Li Sheng, Chen Xiaochun. Low-carbon Economy: Embedded System and Policy Innovation. Science and Technology Management Research, 2009(10), pp. 24-28.

[8] Wei Ruibin. Empirical Research on Social Network Analysis in Keyword Network Analysis. Journal of Information, 2009 (9), pp.33-43.

[9] Zhang Qin, Ma Feicheng. Research Paradigms of Knowledge Management Abroad: Using Co-word Analysis as a Method. Journal of Management Science,2007(12), pp. 26-34. 